\title{
La traducción de los refranes españoles en chino desde una perspectiva intercultural
}

\author{
Jian ZOU \\ jz961@inlumine.ual.es \\ Universidad de Changchun (China) \\ Universidad de Almería (España)
}

Resumen: Cada refrán Ileva el contenido implícito de su cultura nacional. El estudio de la traducción de los refranes españoles en chino desde una perspectiva intercultural ha de basarse en entender bien los contextos culturales, tanto en español como en chino. Este artículo analiza las estrategias de la traducción de los refranes españoles en chino desde una perspectiva intercultural a través de cuatro aspectos: el entorno geográfico, la vida cotidiana, la creencia religiosa y la historia cultural. De esta manera, aspira a favorecer la comprensión entre ambas culturas y a construir puentes que faciliten la comunicación entre las dos comunidades implicadas.

Palabras clave: Traducción Refrán, Cultura, Español, Chino

Abstract: Each proverb carries the implicit content of its national culture. The study of the translation of Spanish sayings into Chinese from an intercultural 
perspective must be based on a good understanding of the cultural contexts, both in Spanish and Chinese. This article analyses the strategies for translating Spanish sayings into Chinese from an intercultural perspective through four aspects: the geographical environment, daily life, religious belief and cultural history. In this way, it aims to foster understanding between the two cultures and to build bridges that facilitate communication between the two communities involved.

Keywords: Translation Refrain, Culture, Spanish, Chinese

\section{Introducción}

Los refranes, $\tan$ abundantes y frecuentes en muchos idiomas, son productos de la sabiduría colectiva de los seres humanos, así como de la experiencia popular. El idioma español y el chino, como dos lenguas de historias largas y culturas coloridas, no pueden ser una excepción. Los refranes componen una parte importante e imprescindible de cada lengua, representando su energía y vivacidad, como señaló Alonso Zamora Vicente, académico, dialectólogo, autor literario, cuando señaló en el prólogo del Refranero españo/que: 


\section{J. Zou}

2019. "La traducción de los refranes españoles en chino desde una perspectiva intercultural" Sabir. International Bulletin of Applied Linguistics, 1: 163-179

“No deja ser fascinante, a ratos estremecedor, comprobar hoy cómo a través de los siglos, la lengua coloquial, la de la esquina y el mercado, la de la tertulia cotidiana en la plaza Mayor, en la proximidad bulliciosa del pilar o bajo la sombra amiga de la olma venerable, la de la pasajera reunión en la reducida, oscura tabernita del lugar se habla, por todos los actores de la sociedad, en ese momento sujeto de la historia, salpicando constantemente la conversación con refranes"

(Zamora Vicente, 2001: 11-12).

Naturalmente, las distancias de todo tipo -históricas, religiosas, circunstanciales, etc- entre España y China, existen por fuerza diferencias entre los refranes españoles y chinos. Así que la traducción de refranes españoles en chino debe superar las barreras culturales de la lengua original para tener en cuenta el significado, la imagen y los hábitos expresivos chinos.

\section{Diferencias culturales reflejadas en refranes españoles y chinos}

\subsection{Diferencias en el entorno geográfico}

Las culturas de los países siempre están presentes en espacios geográficos específicos, por lo tanto, reflejan inevitablemente las características geográficas del país. En el caso de España y China, la geografía presenta características muy 


\section{J. Zou}

2019. "La traducción de los refranes españoles en chino desde una perspectiva intercultural" Sabir. International Bulletin of Applied Linguistics, 1: 163-179

marcadas, nada semejantes entre uno y otro país, entre una y otra cultura. En consonancia con ello, existen muchos refranes que reflejan sus respectivos paisajes naturales, con las consiguientes distancias expresivas.

La oliva es uno de los productos más importantes de España debido a las condiciones geográficas favorables, por lo que hay muchos refranes relacionados con eso. Tales como "El aceite de oliva todo mal quita", "Cada mochuelo a su olivo", "Olivo y aceituno, todo es uno". Sin embargo, el olivo no es un cultivo agrícola universal en toda China, así que en muchas zonas la gente no conoce ni el olivo ni su fruto.

En China existen muchos refranes relacionados con el paisaje natural específico. Por ejemplo:

\section{- “不到黄河心不死"}

Trad. literal: No abandonar hasta llegar al Río Amarillo.

Significado: No abandonar hasta conseguir la meta.

Observaciones: El Río Amarillo es el río más importante de China y en su cuenca se han descubiertos numerosos yacimientos arqueólogos que demuestran la presencia humana interrumpida desde la prehistoria.

- “不登泰山, 不知天地之大”

Trad. literal: El que no llega hasta el Monte Tai, no sabe lo grande del cielo y de la tierra.

Significado: El que no ve grandes cosas no conoce su propia pequeñez. 


\section{J. Zou}

2019. "La traducción de los refranes españoles en chino desde una perspectiva intercultural" Sabir. International Bulletin of Applied Linguistics, 1: 163-179

Observaciones: El Monte Tai es una de las cinco montañas sagradas del taoísmo en China que se ubica en la provincia Shandong, China. Por lo tanto, para comprender plenamente el significado de estos refranes, es necesario conocer primero su connotación geográfica cultural, que se utiliza como metáfora.

\subsection{Diferencias en la vida cotidiana}

Los refranes nacen de la vida, reflejan la vida y están estrechamente relacionados con la vida cotidiana de las personas. Tanto España como China la gastronomía adquiere una notable presencia social y además goza de una gran reputación en todo el mundo. Sin embargo, los hábitos alimentarios de los dos países no son los mismos, como pueden verse en sus respectivos refranes.

El pan, el vino y el queso forman parte de la espléndida cultura gastronómica española, y los refranes hechos de estos elementos son también muy ricos. Por ejemplo, "Al pan, pan, y al vino, vino", "A buen hambre no hay pan duro", "Con pan y vino se anda el camino", "Uvas con queso saben a beso", etc. Los chinos no tienen estas costumbres alimentarias, por lo que no tienen refranes relacionados con dichos elementos.

En china, el arroz es la comida principal en el sur, y la harina de trigo en el norte. Así que existen muchos refranes chinos relacionados con el arroz, la harina y productos de harina. Por ejemplo: 


\section{J. Zou}

2019. "La traducción de los refranes españoles en chino desde una perspectiva intercultural" Sabir. International Bulletin of Applied Linguistics, 1: 163-179

- “巧妇难为无米之炊”

Trad. literal: Una hábil ama de casa no puede hacer la comida sin arroz.

Significado: No se puede trabajar sin materia prima.

\section{- “一样米养百样人”}

Trad. literal: El mismo tipo de arroz alimenta cien tipos de personas.

Significado: En una comunidad, existen diferentes tipos de personas.

- “不当家不知柴米贵”

Trad. literal: Quien no gobierna a la familia no sabe cómo cuesta la leña y el arroz.

Significado: Sin experiencia personal, no se conoce la dificultad del trabajo de la vida.

\subsection{Diferencias en la creencia religiosa}

La creencia religiosa es un aspecto importante de la actividad espiritual de las personas y tiene cierta influencia en la cultura nacional. La religión católica ha sido la más importante en España. La mayoría de los españoles son culturalmente católicos, con la figura de Díos como elemento central de su sistema de valores teológicos. De ahí que muchos refranes españoles estén vinculados a la práctica religiosa. Por ejemplo,

- "Dios los cría, y ellos se juntan",

- "A quien Dios se la dé, San Pedro se la bendiga", 
2019. "La traducción de los refranes españoles en chino desde una perspectiva intercultural" Sabir. International Bulletin of Applied Linguistics, 1: 163-179

- "Dios aprieta, pero no ahoga",

- "Dios da el frío conforme la ropa",

- "Dar al César lo que es del César y a Dios lo que es de Dios", etc.

En cuanto a la situación china, los chinos adoran el cielo y creen que es el soberano de la naturaleza. Así que existen muchos refranes sobre el cielo.

- “天无绝人之路”

Trad. literal: El cielo no cierra el camino a los hombres.

Significado: Este refrán tratar de consolar a quien está sufriendo algún infortunio, afirmando que siempre hay una salida.

- “皇天不负苦心人”

Trad. literal: El cielo no decepciona a quien se esfuerza.

Significado: Las personas quienes se esfuerzan pueden lograr lo que quieren.

- “谋事在人, 成事在天”

Trad. literal: El hombre plantea, y el cielo decide.

Significado: La planificación se basa en los esfuerzos subjetivos humanos y los resultados depende de la voluntad del cielo.

Además, el budismo fue introducido en China hace más de dos mil años, y todos los aspectos de China están impregnados de influencias budistas. Los refranes siguientes son buenos ejemplos. 


\section{J. Zou}

2019. "La traducción de los refranes españoles en chino desde una perspectiva intercultural" Sabir. International Bulletin of Applied Linguistics, 1: 163-179

\section{- “临时抱佛脚”}

Trad. literal: Abrazar los pies de Buda a última hora.

Significado: Apresurarse a pedir ayuda a última hora.

\section{- “放下屠刀，立地成佛”}

Trad. literal: Dejar de lado su cuchillo de carnicero y convertirse instantáneamente en Buda.

Significado: Una vez que el malhechor reconoce su culpa y está decidido a corregirla, puede convertirse rápidamente en un hombre bueno.

\subsection{Diferencias en la historia cultural}

Detrás de los refranes de cada país hay un mensaje cultural, lo que dificulta la traducción mutua de los refranes en los que impregnan el contenido único de las culturas nacionales de España y China. Muchos refranes españoles están relacionados con la Biblia, la historia y las obras literarias.

- "Ojo por ojo, diente por diente"

Significado: Se refiere a la venganza. Causar el mismo daño que uno recibió. Observaciones: Proviene de Mateo 5:38 "Oísteis que fue dicho: Ojo por ojo, y diente por diente".

- "A buenas horas, mangas verdes"

Significado: Se censura la demora en atender las necesidades o en solucionar los problemas. 


\section{J. Zou}

2019. "La traducción de los refranes españoles en chino desde una perspectiva intercultural" Sabir. International Bulletin of Applied Linguistics, 1: 163-179

Observaciones: El origen de esta frase se remonta a los tiempos de los cuadrilleros de la Santa Hermandad creados por los Reyes Católicos, que como casi nunca llegaban a tiempo para capturar a los malhechores, los delitos quedaban impunes. Vestían un uniforme con mangas verdes.

Muchos refranes chinos se basan en figuras históricas específicas, obras literarias, etc., que tienen un marcado color nacional.

\section{- “事后诸葛亮”}

Trad. literal: Hacerse Zhuge Liang después de lo sucedido.

Significado: Se censura la demora en atender las necesidades o en solucionar los problemas.

Observaciones: "Zhuge Liang" es un personaje en la novela clásica china La Historia de los Tres Reinos. Es un personaje muy inteligente que siempre sabe prevenir lo que va a suceder.

- “说曹操, 曹操就到"

Trad. literal: Hablando del Cao Cao, y Cao Cao asoma.

Significado: Describe la presencia inesperada de la persona de que habla. Observaciones: El origen del refrán es la novela clásica china La Historia de los Tres Reinos. Un día, un hombre recomendó a cao cao al emperador Han Xian, diciendo que podía proteger la seguridad del emperador. Justo llegó Cao Cao cuando el emperador estaba a punto de llamarlo. 


\section{J. Zou}

2019. "La traducción de los refranes españoles en chino desde una perspectiva intercultural" Sabir. International Bulletin of Applied Linguistics, 1: 163-179

\section{Estrategias de traducción de refranes españoles en chino}

El filósofo y traductor alemán Schleiermacher (1813) planteó la existencia de dos grandes opciones en "Sobre los diferentes métodos de traducción": o el traductor deja al autor en paz, tanto como le sea posible, y mueve al lector hacia él; o deja al lector en paz, tanto como sea posible, y mueve al autor hacia él (Lefevere, 1992: 149). Siguiendo esos planteamientos, Venuti propuso dos métodos de traducción: la extranjerización y la domesticación (Venuti, 1995: 20). La cultura aparece como el principal obstáculo para la comunicación intercultural y el principal problema en la traducción. La extranjerización y la domesticación son los principales métodos para tratar la información cultural en la traducción.

La domesticación utiliza un estilo transparente y fluido que minimiza la extrañeza para el lector de la traducción (Shuttleworth, 2014: 43-44). La extranjerización se consigue a través de conservar algunos componentes originales, lo que supone romper intencionalmente las normas de la cultura objetivo (Shuttleworth, 2014: 59). En comparación con la extranjerización, la domesticación tiene sus méritos: no solo hace que los lectores sienten lo maravilloso de la coincidencia de diferentes culturas, sino que también hace inteligible el texto traducido, por lo tanto, apropiado para los lectores. Sin embargo, este tipo de inteligibilidad sacrifica informaciones complementarias entre diferentes culturas, convirtiendo los componentes heterogéneos de una 
2019. "La traducción de los refranes españoles en chino desde una perspectiva intercultural" Sabir. International Bulletin of Applied Linguistics, 1: 163-179

cultura en una cultura conocida. Así que la domesticación solo hace que los lectores repasen su cultura y su idioma, debilitando la posibilidad de impregnarse de la cultura de origen.

Concretando esa problemática en la traducción de los refranes, como se han mencionado más arriba, la mayoría de los refranes provienen de la vida y la producción de la gente común, y los demás se originan de la historia, la creencia religiosa y la obra literaria. Se puede decir, en gran medida que el refrán es como una enciclopedia lingüística cultural de las costumbres nacionales, experiencias vitales, la visión del mundo, el medio ambiente, la historia, la religión, etc. Por lo tanto, parece conveniente ponderar ambos factores. Ha de basarse en la extranjerización, sin desatender una aplicación flexible de la domesticación, de cara a mostrar las diferentes características y enriquecer la cultura.

\subsection{Sustitución}

En el caso de que los refranes tengan la misma o similar connotación cultural, manejen una imagen cultural análoga o transmitan al lector el mismo sentimiento emocional, se puede usar la estrategia de sustitución.

- "A río revuelto, ganancia de pescadores".

Equivalencia en chino: “浑水摸鱼”. 
2019. "La traducción de los refranes españoles en chino desde una perspectiva intercultural" Sabir. International Bulletin of Applied Linguistics, 1: 163-179

Es lo mismo tanto en el significado literal como el significado implícito en el refrán español "A río revuelto, ganancia de pescadores" y el Cheng $Y u^{1}$ "浑 水摸鱼". Ambos expresan una verdad observada por los españoles y los chinos desde la naturaleza, de la que se extraen idénticas consecuencias vitales: en la vida: sacar provecho de las situaciones de caos o desorden.

- $\quad$ "Año de nieves, año de bienes".

Equivalencia en chino: “瑞雪兆丰年”.

El refrán español "Año de nieves, año de bienes" y el refrán chino "瑞雪兆 丰年" reflejan igualmente la suma de las experiencias vitales de los dos países, en el sentido de que el año con mucha nieve es favorable para las buenas cosechas, porque, gracias a la nieve, la tierra labrada se mantiene húmeda y esponjosa para que los cereales crezcan debidamente.

\subsection{Sustitución con nota}

En el caso de que los refranes tengan distinta connotación cultural, una imagen cultural diferente, o sea, rasgos semánticos no equivalentes, pero expresen el mismo significado y le dan al lector el mismo sentimiento emocional, se puede usar la estrategia de sustitución con nota.

- "A cada cerdo le llega su San Martín".

Equivalencia en chino "恶有恶报[Nota]".

\footnotetext{
Cheng $Y u$ es una expresión idiomática característica del idioma chino.
} 


\section{J. Zou}

2019. "La traducción de los refranes españoles en chino desde una perspectiva intercultural" Sabir. International Bulletin of Applied Linguistics, 1: 163-179

[Nota]San Martín es una festividad que se celebra el 11 de noviembre en honor de Martín de Tours, siendo una fecha muy señalada en muchos pueblos de la geografía española pues es cuando tiene lugar la matacía o matanza del cerdo (Rodríguez; Romera, 1994: 557).

En este caso, el refrán español "A cada cerdo le llega su San Martín" indica que no queda impune el comportamiento del malvado, pues, tarde o temprano, le llegará el momento de pagar su culpa. El refrán chino “恶有恶报" significa tanto literalmente como implícitamente que quien ha obrado mal recibe su merecido. Así se puede ver que los dos expresan la misma relación de causa y consecuencia que resumieron la gente de los dos países a pesar de por los distintos rasgos semánticos.

\subsection{Traducción literal}

Debido a las diferencias entre la cultura de los dos países, la mayoría de los refranes llevan connotaciones culturales diferentes, por lo tanto, en el caso de que no existan equivalencias en refranes chinos ni haya dificultades en la comprensión de las connotaciones e imágenes culturales que expresan los refranes españoles, debe aplicar la traducción literal. Por una parte, no pierde las puras características culturales de la lengua original, por otra, no dificulta el entendimiento de la traducción de los lectores.

- "A mal tiempo, buena cara". 
2019. "La traducción de los refranes españoles en chino desde una perspectiva intercultural" Sabir. International Bulletin of Applied Linguistics, 1: 163-179

\section{Traducción literal: “笑对坏天气”.}

En este ejemplo, no existe una equivalencia el refrán español "A mal tiempo, buena cara" en chino, pero la actitud de ser optimista en frente de los momentos difíciles que expresa el refrán es un tipo de actitud universal que fácilmente puede ser entendida por los hablantes de otra cultura sin ningún obstáculo. Así que la traducción literal es una buena opción.

\subsection{Traducción literaria con nota}

En el caso de que no existan equivalencias en refranes chinos ni se entiendan por las connotaciones e imágenes culturales que expresan los refranes españoles, debe aplicar la traducción literaria con nota. De esta manera, por una parte, no rompe la experiencia lectora, como sucedería con una novela, una noticia o un ensayo, etc., por otra parte, con la nota que explica cómo es el refrán original, las connotaciones e imágenes culturales, no sacrifican las informaciones culturales que expresa. Sin embargo, si trata de una recopilación de refranero bilingüe, es aconsejable poner tanto la traducción literal como la traducción literaria, es decir, una visión completa, porque los objetivos de un refranero bilingüe son difundir los idiomas a través de los refranes, facilitar la enseñanza/aprendizaje de idiomas y proporcionar un instrumento de consulta a los traductores o interesados.

- "A otro perro con ese hueso". 
Traducción literal: “把骨头给别的狗”.

Traducción propuesta: "骗鬼去吧[Nota]".

[Nota] El perro es símbolo de fidelidad e ingenuidad. Cuando ve algo parecido a un hueso, sale corriendo hacia él. En este caso, el refrán expresa que la persona no está dispuesta a ser engañada y a ser aprovechada por el mentiroso.

\section{Conclusión}

Después de lo anterior se puede llegar a la conclusión de que, por un lado, los refranes siempre están relacionados con un contexto cultural particular, ya sea que provengan de costumbres populares, de creencias religiosas o de obras literarias. Son tesoros nacionales que se han acumulado a lo largo de una larga historia. Por otro, debido a las características culturales que contienen los refranes, es muy importante adoptar las normas adecuadas para traducir el contenido cultural. La extranjerización y la domesticación son dos medios principales para traducirlo. A partir de la perspectiva de difundir las culturas a través de los refranes, facilitar la lectura de la traducción y motivar el interés de los lectores, ha de basarse en la extranjerización la traducción de los refranes y aplicarse la domesticación flexiblemente.

\section{Bibliografía}


Canellada, M. J. y B. Pallares.

2001, Refranero español: refranes, clasificación, significación y uso. Vol. 8. Madrid: Castalia.

Lefevere, A.

1992. Translation/History/Culture: A Sourcebook. Londres y Nueva York: Routledge.

Li, T.

2016. 精编西汉汉西成语习语词典 [Diccionario de proverbios y frases españo/chino/ chino-español, Beijing: Editorial de Universidad de Lengua y Cultura de Beijing.

Rodríguez, J. M. y J. M. Romera.

1994. El porqué de los dichos: sentido, origen y anécdota de los dichos, modismos y frases proverbiales de España con otras muchas curiosidades. Pamplona: Gobierno de Navarra, Departamento de Educación y cultura.

Schleiermacher, F.

1813. "On the different methods of translating" en The translation studies reader 2. 43-63.

Sevilla Muñoz, J. y M.I.T. Zurdo Ruiz-Ayúcar, [dir.]

2009. Refranero multilingüe. Madrid. Instituto Cervantes (Centro Virtual Cervantes). Consulta: <http://cvc.cervantes.es/lengua/refranero/> 
J. Zou

2019. "La traducción de los refranes españoles en chino desde una perspectiva intercultural" Sabir. International Bulletin of Applied Linguistics, 1: 163-179

Shuttleworth, M.

2014. Dictionary of translation studies. Londres: Routledge.

Venuti, L.

1995. The translator's invisibility: A history of translation. Londres: Routledge.

Wen,Duanzheng.

2011. 中国浐语大辞典 [Gran diccionario de refranes chinos], Shanghai: Editorial de Diccionario de Shanghai. 